\title{
RNA-binding protein altered expression and mislocalization in MS
}

Katsuhisa Masaki, MD, PhD, Yoshifumi Sonobe, PhD, Ghanashyam Ghadge, PhD, Peter Pytel, MD, Paula Lépine, MSc, Florian Pernin, MSc, Qiao-Ling Cui, MD, PhD, Jack P. Antel, MD, Stephanie Zandee, PhD, Alexandre Prat, MD, PhD, and Raymond P. Roos, MD

Neurol Neuroimmunol Neuroinflamm 2020;7:e704. doi:10.1212/NXI.0000000000000704

\author{
Correspondence \\ Dr. Roos \\ rroos@neurology.bsd.uchicago.edu
}

\begin{abstract}
Objective

To determine whether there are nuclear depletion and cellular mislocalization of RNA-binding proteins (RBPs) transactivation response DNA-binding protein of $43 \mathrm{kDa}$ (TDP-43), fused in sarcoma (FUS), and polypyrimidine tract-binding protein (PTB) in MS, as is the case in amyotrophic lateral sclerosis (ALS) and oligodendrocytes infected with Theiler murine encephalomyelitis virus (TMEV), we examined MS lesions and in vitro cultured primary human brain-derived oligodendrocytes.
\end{abstract}

\section{Methods}

Nuclear depletion and mislocalization of TDP-43, FUS, and PTB are thought to contribute to the pathogenesis of ALS and TMEV demyelination. The latter findings prompted us to investigate these RBPs in the demyelinated lesions of MS and in in vitro cultured human brain-derived oligodendrocytes under metabolic stress conditions.

\section{Results}

We found (1) mislocalized TDP-43 in oligodendrocytes in active lesions in some patients with MS; (2) decreased PTB1 expression in oligodendrocytes in mixed active/inactive demyelinating lesions; (3) decreased nuclear expression of PTB2 in neurons in cortical demyelinating lesions; and (4) nuclear depletion of TDP-43 in oligodendrocytes under metabolic stress induced by low glucose/low nutrient conditions compared with optimal culture conditions.

\section{Conclusion}

TDP-43 has been found to have a key role in oligodendrocyte function and viability, whereas PTB is important in neuronal differentiation, suggesting that altered expression and mislocalization of these RBPs in MS lesions may contribute to the pathogenesis of demyelination and neurodegeneration. Our findings also identify nucleocytoplasmic transport as a target for treatment. 


\section{Glossary}

ALS = amyotrophic lateral sclerosis; FUS = fused in sarcoma; $\mathbf{L G}=$ low glucose $; \mathbf{L P S}=$ lipopolysaccharide $; \mathbf{m R N A}=$ messenger RNA; NAGM = normal-appearing gray matter; NAWM = normal-appearing white matter; $\mathbf{P I}=$ propidium iodide; $\mathbf{P P W M}=$ periplaque white matter; $\mathbf{P T B}=$ polypyrimidine tract-binding protein; $\mathbf{R B P}=\mathrm{RNA}$-binding protein; TDP-43 = transactivation response DNA-binding protein of $43 \mathrm{kDa}$; TMEV = Theiler murine encephalomyelitis virus; $\mathbf{T N F a}=$ tumor necrosis factor alpha.

The pathologic mechanisms driving demyelination and neurodegeneration in MS remain poorly understood. In the present study, we investigated the expression and localization of 3 RNA-binding proteins (RBPs) ${ }^{1}$ in MS and in cultured oligodendrocytes exposed to metabolic stress. These RBPs predominantly reside in the nucleus, but can shuttle into the cytoplasm.

We previously found that RBP polypyrimidine tract-binding protein (PTB) is mislocalized to the cytoplasm in Theiler murine encephalomyelitis virus (TMEV)-infected cells—and hypothesized that this nuclear depletion plays a role in TMEV-induced disease pathogenesis. ${ }^{2,3}$ Because amyotrophic lateral sclerosis (ALS) and TMEV target similar neural cell types and because nuclear depletion and mislocalization of RBPs transactivation response DNA-binding protein of $43 \mathrm{kDa}$ (TDP-43) and fused in sarcoma (FUS) have been implicated in ALS pathogenesis, we next investigated these RBPs in TMEV infections. ${ }^{4}$ We subsequently found that TDP-43 and FUS, in addition to PTB, were mislocalized in demyelinating lesions in TMEV-infected neural cells, including oligodendrocytes. ${ }^{4}$

Because TMEV-induced demyelinating disease serves as an experimental model of MS, we next examined the expression pattern and localization of these RBPs in MS. We now report nuclear depletion and mislocalization of TDP-43 and PTB in MS lesions and in vitro cultured oligodendrocytes. Recent publications stress the importance of TDP- 43 for oligodendrocyte survival and myelination, ${ }^{5}$ and of PTB for neuronal differentiation, ${ }^{6,7}$ suggesting a role for these RBPs in MS pathogenesis and the potential importance of nucleocytoplasmic transport as a target for treatment.

\section{Methods}

\section{Ethics statement}

The study involved tissue from human subjects and was approved by the University of Chicago Institutional Review Board for Clinical Research. Informed written consent for an autopsy at the University of Chicago was obtained from an immediate member of the deceased's family. The autopsies on patients with $\mathrm{MS}^{8}$ from the Centre de Recherche du Centre Hospitalier de l'Université de Montréal had informed consent and were in accordance with institutional guidelines and approval by the local Centre Hospitalier de l'Université de Montréal ethics committee (HD04.046 and BH07.001). ${ }^{9}$ The use of tissue from the Montreal Neurological Institute, McGill University, was approved by the McGill University Health Center Research Ethics Board. The human samples that were used are described in the e-methods (links.lww.com/NXI/A221).

\section{Staging of demyelinating lesions}

We classified MS plaques into 3 stages ${ }^{10}$ based on the density of macrophages: (1) active-lesions densely and diffusely infiltrated with macrophages, (2) mixed active/inactivelesions with macrophages restricted to the periphery, and (3) inactive-lesions with no increase in macrophage numbers within the plaque. We classified cortical plaques into 3 subtypes: leukocortical (involving both white matter [WM] and cortex), intracortical, and subpial (superficial cortical).

\section{Semiquantitative analysis of RBP mislocalization}

Tissue preparation and immunohistochemistry/ immunofluorescence methods are described in the Supplement. Sections from blocks of the cerebral cortex and WM in all MS cases were stained with 3,3'-Diaminobenzidine or by fluorescence for RBPs that included TDP-43, PTB1, PTB2, and FUS. A semiquantitative assessment of RBP nuclear depletion and mislocalization or decreased expression in demyelinating lesions was performed by taking digital photographs with a complementary metal oxide semiconductor camera at a resolution of $1,636 \times 1,088$ pixels with a $\times 20(0.75 \mathrm{NA})$ objective. At least 3 different photographs of areas of 1 lesion that were more than $1 \mathrm{~mm}$ apart from each other in $\mathrm{x}$ and $\mathrm{y}$ directions were randomly taken for every demyelinating lesion. At least 100 neuronal or glial cells per each area were identified on the basis of cytologic features ${ }^{11}$ and scored based on the degree of mislocalization or decreased nuclear expression of RBPs compared with normal-appearing WM (NAWM) from the same case stained at the same time: - no or minimal; + mild (10-30 cells); ++ moderate $(30-100$ cells $) ;+++$ cases prominent ( $>100$ cells) (see table e-1, links.lww.com/NXI/A220).

\section{In vitro studies}

In vitro cultured primary oligodendrocytes using a previously described cell isolation procedure have been found to have a purity of $>90 \%$ and express mature oligodendrocyte gene markers with few progenitor markers. ${ }^{12,13}$ The tissue is collected from surgical resections of nonmalignancy cases associated with epilepsy; the tissue is derived from a site distant from visible pathology. ${ }^{12,13}$ Aliquots are routinely provided to a neuropathologist to exclude any distinct abnormalities. The tissue is mainly subcortical WM, but does contain fragments of gray matter. 
In the present study, oligodendrocytes were isolated and cultured from samples of 4 surgical resections ( 3 adult cases: 2 males, ages 57 and 38 years, and 1 female, age 51 years, and 1 pediatric case: male, age 7 years). ${ }^{12,13}$ The isolation technique involved initial dissociation of tissue using trypsin digestion followed by Percoll gradient centrifugation to remove myelin. The total cell fraction was plated onto a noncoated flask that was kept overnight at $37^{\circ} \mathrm{C}$ to allow adhesion of the microglia fraction. Floating cells were then recovered $\left(>90 \%\right.$ were $\mathrm{O}^{+}$) and plated into 12 well poly-L-lysine and extracellular matrixcoated chamber slides (30,000 cells per well) in defined medium (referred to as N1) consisting of Dulbecco Modified Eagle Medium-F12 (Sigma-Aldrich, St. Louis, MO) supplemented with N1 (Sigma-Aldrich), 0.01\% bovine serum albumin, $1 \%$ penicillin-streptomycin, B27 (Invitrogen, Burlington, $\mathrm{ON}, \mathrm{CA}$ ), platelet-derived growth factor with $2 \mathrm{~A}$ subunits (10 $\mathrm{ng} / \mathrm{mL})$, basic fibroblast growth factor $(10 \mathrm{ng} / \mathrm{mL})$, and triiodothyronine ( $2 \mathrm{nM})$ (Sigma-Aldrich). After 4 days, media in individual chambers were replaced with fresh $\mathrm{N} 1$ or with Dulbecco Modified Eagle Medium with $0.25 \mathrm{~g} / \mathrm{L}$ glucose (referred to as low glucose [LG]). After an additional 2 or 6 days of N1 or LG treatment, cells were incubated with monoclonal O4 antibody and propidium iodide (PI) for 15 minutes at $37^{\circ} \mathrm{C}$. Cells were fixed with $4 \%$ paraformaldehyde for 10 minutes at room temperature and then stained with a secondary antibody directed against O4, goat anti-mouse IgM conjugated to AF-647 (SouthernBiotech, Birmingham, AL). After permeabilization buffer with $0.1 \%$ Triton X-100, the cells were stained with polyclonal anti-TDP-43 antibody (Proteintech, Rosemont, IL) for 1 hour at $37^{\circ} \mathrm{C}$ followed by goat anti-rabbit polyclonal antibody conjugated to AF-488 and Hoescht 33,258 (Invitrogen) for 30 minutes. Cells were then examined using an epifluorescent microscope (Zeiss, Oberkochen, Germany) to determine the percent of $\mathrm{O} 4$ cells that were $\mathrm{PI}^{+}$cells and $\%$ of cells that showed predominantly nuclear vs cytoplasmic distribution of TDP-43. Data were derived by blinded observers counting 75-100 cells per condition. Data between LG and N1 conditions were compared using a paired $t$ test.

\section{Statistical analysis}

Data were analyzed using GraphPad Prism version 7.0a and are expressed as mean \pm standard error of the mean. Significance was assessed using the Student $t$ test, and $p$ values less than 0.05 were considered significant. A 95\% CI was calculated for the difference in frequency of RBP mislocalization or level of RBP expression between a cell type in the demyelinating lesion vs periplaque white/gray matter.

\section{Data availability}

Any data not published within the article will be shared by request from any qualified investigator in anonymized form.

\section{Results}

\section{TDP-43 in ALS}

In ALS, TDP-43 is depleted from the nucleus in some motor neurons and localized in aggregates in the cytoplasm (figure 1A, arrows), whereas other neurons and glial cells have TDP-43 in its normal location in the nucleus (figure $1, \mathrm{~A}$ and $\mathrm{B}$, arrowhead). At times, phosphorylated TDP-43 is present in the cytoplasmic aggregates (figure 1C). In contrast, FUS maintained its normal nuclear localization in cells in the same region that had cells with TDP-43 mislocalization (figure 1D). PTB1 was not detected in motor neurons (figure $1 \mathrm{E}$ ) because it is known to have a limited distribution in this cell type. ${ }^{14}$ PTB2 was present in motor neurons, but, like FUS, had a normal nuclear localization (figure $1 \mathrm{~F}$ ). In contrast to these findings in ALS, a predominant nuclear localization of TDP-43 was present in neurons and oligodendrocytes in human control CNS tissue from a patient with myasthenia gravis (figure $1, \mathrm{G}$ and $\mathrm{H}$ ). With immunofluorescent staining, we examined an additional case of ALS and another CNS control case from a patient with muscular dystrophy. TDP-43 was normally expressed in the nucleus of some motor neurons in the ALS case, whereas nuclear depletion of TDP-43 with skein-like inclusions was seen in the cytoplasm of other motor neurons (figure $1, \mathrm{I}-\mathrm{K}$ ). In the control case, TDP-43 was seen in nuclei of cortical neurons (figure 1L) and spinal cord motor neurons (figure 1M).

\section{Altered localization and expression of RBPs in oligodendrocytes in WM plaques}

TDP-43 was mislocalized to the cytoplasm in glial cells in active demyelinating lesions from patients MS\#3 and 13 to a moderate degree (table e-1, links.lww.com/NXI/A220) (MS\#3-figure 2, A-H). Double immunofluorescence demonstrated that this mislocalization was present in CNPasepositive oligodendrocytes to a significant extent (figure 2, I and J); the nuclear depletion and cytoplasmic mislocalization were statistically significantly greater when compared with oligodendrocytes in the periplaque WM (PPWM) (95\% CI, 31.89-61.61; $p=0.0003$ ) (figure 2, I and J). Similar findings were also present in all 3 active demyelinating plaques in the case of MS\#13 (figure e-1, links.lww.com/NXI/A219). Cells with TDP-43 mislocalization had normal morphology and no evidence of cleaved caspase- 3 staining, suggesting that these oligodendrocytes were not dying. Although the oligodendrocytes in active plaques in the CNS tissue from MS\#3 and 13 exhibited TDP-43 mislocalization, this was not the case with the active plaques from a biopsy of a tumefactive MS lesion in MS\#4 and from another MS case with 3 active plaques. No abnormalities were found with respect to the normal nuclear localization and expression of FUS in active plaques.

In addition to our finding of mislocalization of TDP-43 in some active plaques, there was decreased expression of PTB1 in oligodendrocytes in mixed active/inactive demyelinating lesions (MS\# 2, 6, 10-13, table e-1, links.lww. com/NXI/A220); however, cytoplasmic mislocalization of PTB1 was not seen in these lesions. In addition, TDP-43 and FUS were present in the nucleus in mixed active/inactive demyelinating lesions. The decreased expression of PTB1 ranged from mild to prominent (table e-1). Although PTB1 had its expected nuclear staining in NAWM in the case of MS\#10 (figure 3, B and E), there was markedly decreased 


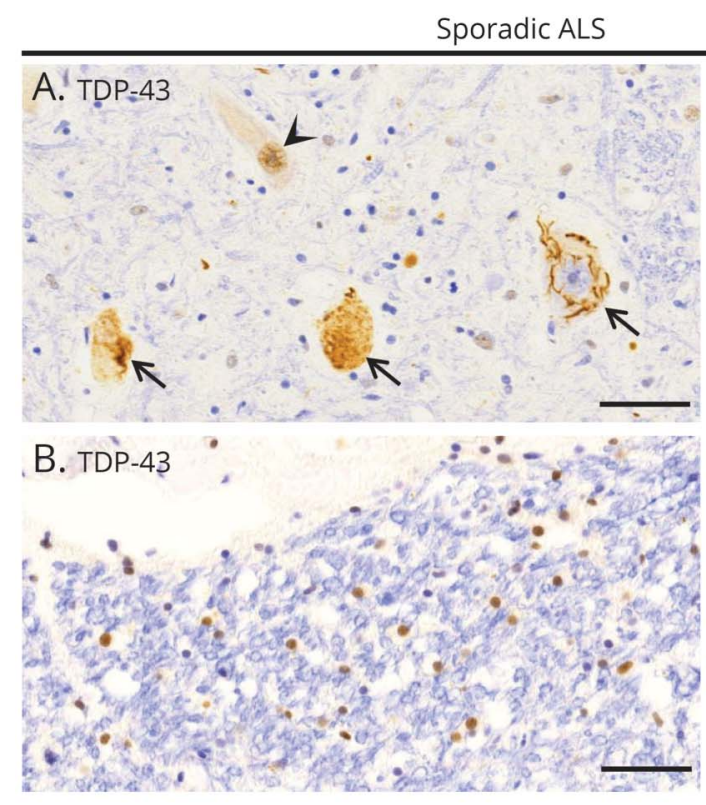

Sporadic ALS
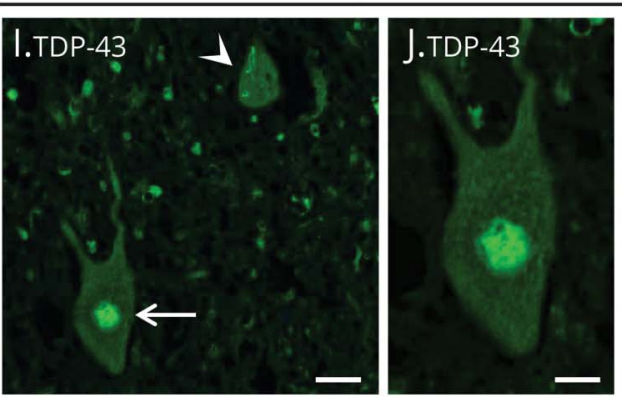
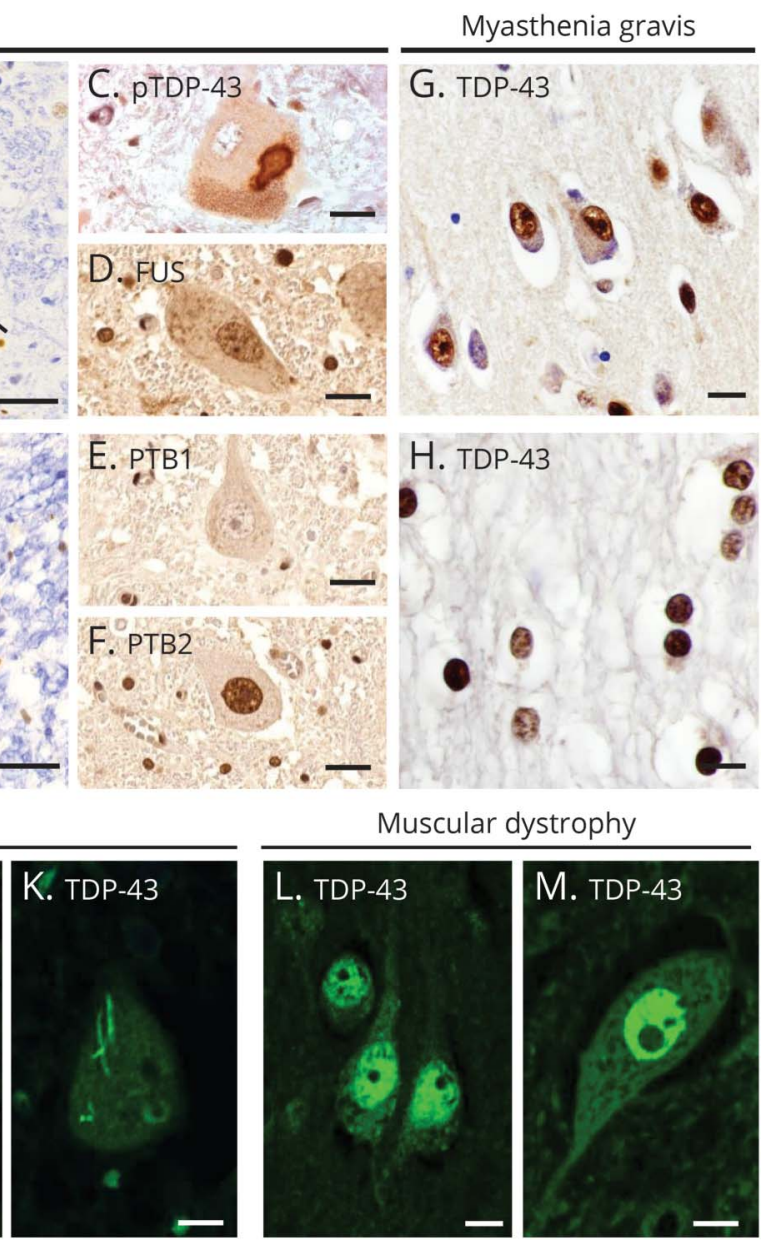

Muscular dystrophy

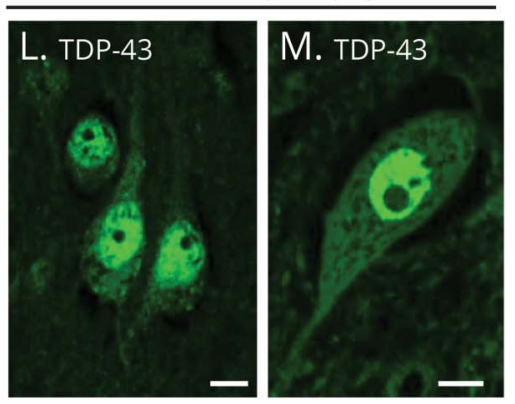

(A-F) A case of sporadic ALS. (A) TDP-43 is expressed normally in the nucleus of some spinal cord motor neurons (arrowhead), but depleted from the nucleus of affected motor neurons, forming aggregates (large arrows). (B) TDP-43 is in its normal nuclear location in glial cells in spinal cord white matter. (C) A cytoplasmic inclusion in spinal cord motor neurons contains pTDP-43. As expected in normal motor neurons, (D) FUS is present in the nucleus, (E) PTB1 is not present, and (F) PTB2 is present in the nucleus. ( $\mathrm{G}$ and $\mathrm{H}$ ) A CNS control patient with myasthenia gravis. Expression of TDP-43 is mainly seen in the nuclei of cortical neurons (G) and white matter oligodendrocytes (H). (I-K) An additional case of sporadic ALS. (I) Immunofluorescent staining for TDP-43 shows normal expression in the nucleus of 1 spinal cord motor neuron (arrow), but mislocalization to the cytoplasm (arrowhead) in another neuron. ( and K) High magnification view of the 2 motor neurons shown in panel I, with normal nuclear expression of TDP-43 in 1 neuron (I), but nuclear depletion of TDP-43 along with a skein-like cytoplasmic inclusion in another neuron (K). (L and M) A CNS control patient with muscular dystrophy. TDP-43 expression is seen in the nucleus of cortical neurons (L) and spinal cord motor neurons (M). Scale bars: $50 \mu \mathrm{m}(\mathrm{A}$ and $\mathrm{B}), 20 \mu \mathrm{m}(\mathrm{C}-\mathrm{G}, \mathrm{I})$, and $10 \mu \mathrm{m}(\mathrm{H}, \mathrm{J}-\mathrm{M})$. ALS = amyotrophic lateral sclerosis; FUS = fused in sarcoma; PTB = polypyrimidine tract-binding protein; pTDP-43 = phosphorylated TDP-43; TDP-43 = transactivation response DNA-binding protein of $43 \mathrm{kDa}$.

expression in the nuclei and cytoplasm of CNPase-positive oligodendroglia in demyelinated and partly remyelinated lesions (figure 3, C, D, F, and G); this lesion had macrophages present in the periphery as typical of active-inactive plaques. The decrease in expression was statistically significant compared with oligodendrocytes in the PPWM (95\% CI, 28.65-64.85; $p=0.0007$ ) (figure $3 \mathrm{H}$ ). Cells with decreased PTB1 expression had normal morphology, and there was no evidence of caspase-3 staining. In the case of MS\#6, PTB1 expression was also diminished in mixed active/ inactive demyelinating lesion (figure 3, I-K); again, macrophages were present in the periphery of this plaque. The decrease in expression was statistically significant compared with oligodendrocytes in the PPWM (95\% CI, 28.60-55.40; $p=0.0003$ ) (figure $3 \mathrm{~K}$ ).

\section{Alteration of RBPs in cortical plaques}

Leukocortical mixed active/inactive demyelinating lesions from patients MS\#2, 8, 10-12 had mild to moderate diminution of PTB2 expression in neurons within the demyelinated area compared with neurons in adjacent normal-appearing gray matter (NAGM) (MS\#2-figure 4, A-H, MS\#10—figure 4, I-L) (table e-1, links.lww.com/NXI/A220). Although the expression of PTB2 was decreased in the nucleus in these cells, there was no evidence of cytoplasmic mislocalization or aggregate formation of PTB2 (figure 4, E-G). The decrease in PTB2 expression in cortical neurons in leukocortical plaques in the case of MS\#2 and \#10 was statistically significant compared with cortical neurons in the periplaque gray matter (MS\#2; 95\% CI, 42.22-72.28; $p<0.0001$, MS\#10; 95\% CI, 40.70-67.80; $p<$ 0.0001 ) (figure $4, \mathrm{H}$ and $\mathrm{L}$ ). In contrast to these findings, the expression of TDP-43 and FUS in neurons in leukocortical 
Figure 2 Altered expression of TDP-43 in oligodendrocytes of MS plaques

Active and demyelinating lesion (MS\#3)
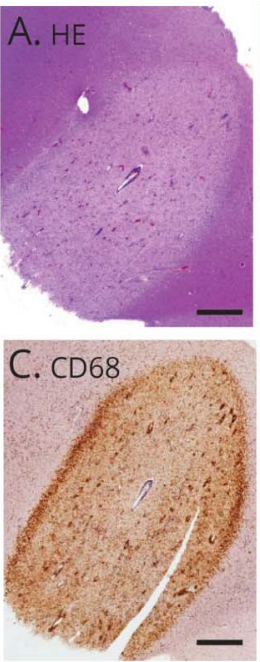
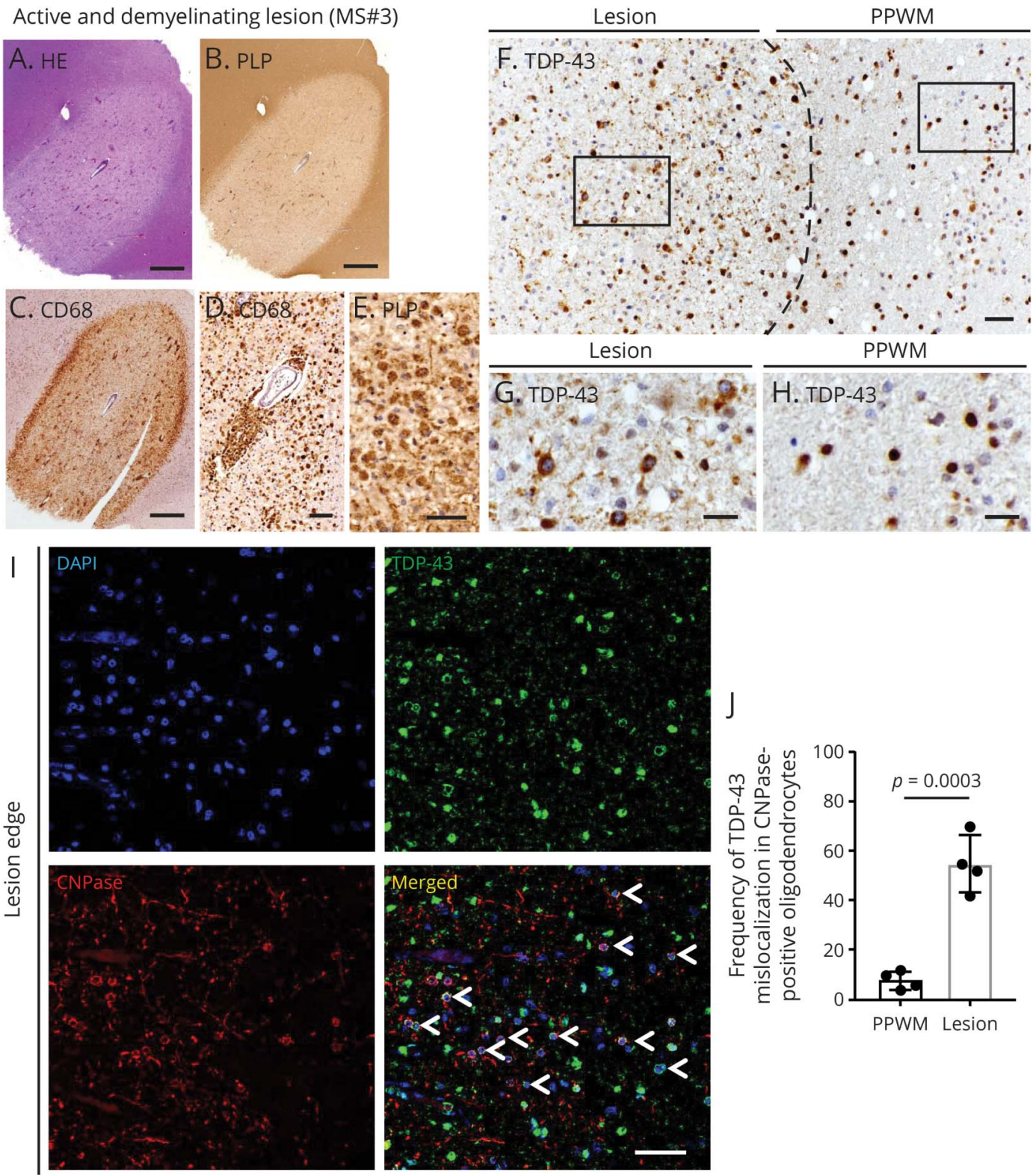

Lesion

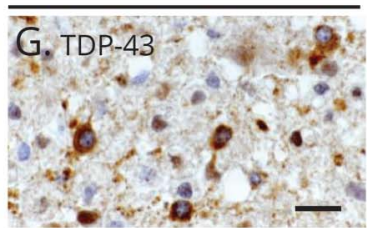

PPWM
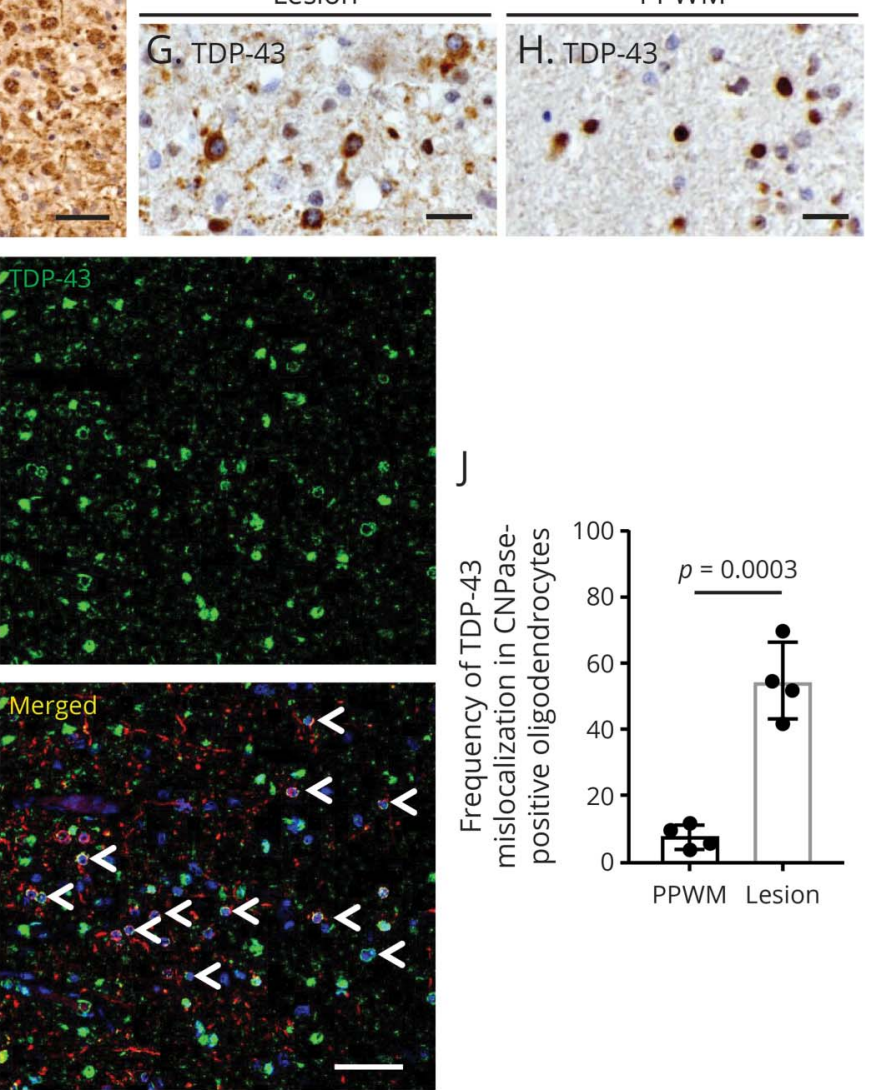

(A-G) An active and demyelinating lesion from MS\#3. (A) Hematoxylin and eosin staining shows perivascular inflammation with mononuclear cell infiltration. (B and C) Immunostaining for proteolipid protein and CD68 identifies a marked loss of myelin with dense infiltration of macrophages. (D) Numerous CD68-positive macrophages are seen in the perivascular area and parenchyma of the lesion center. (E) Foamy macrophages phagocytosing proteolipid protein-positive myelin debris. (F-H) Boundary of active demyelinating lesion of MS\#3. (F) The dashed line shows the approximate boundary between the demyelinating lesion and PPWM. (G) High magnification view of the square in the demyelinating lesion shown in panel F. TDP-43 is nuclear depleted and mislocalized to the cytoplasm in some of the glial cells in the demyelinating lesion. (H) High magnification view of the square in PPWM. TDP-43 is predominantly localized to the nuclei of glial cells in PPWM. (I) Double immunofluorescence shows mislocalization of TDP-43 in CNPase-positive oligodendrocytes at the edge of a demyelinating plaque (arrowheads). () TDP-43 nuclear depletion and cytoplasmic mislocalization in CNPase-positive oligodendrocytes. TDP-43 mislocalization in oligodendrocytes is significantly greater in demyelinating lesions than PPWM. Each dot for this quantitation and subsequent ones represents a photograph from a separate region of the plaque. Scale bars: $1 \mathrm{~mm}(A-C), 50 \mu \mathrm{m}(D-F, I)$, and $20 \mu \mathrm{m}(\mathrm{G}$ and $H)$. DAPI = 4',6-diamidino-2-phenylindole; PPWM = periplaque white matter; TDP-43 = transactivation response DNA-binding protein of 43 kDa.

plaques and of TDP-43, FUS, and PTB2 in neurons of intracortical and subpial plaques had a normal expression in the nuclei and did not differ from that in NAGM (table e-1).

\section{TDP-43 proteinopathy in in vitro primary human oligodendrocytes}

We cultured primary human oligodendrocytes in a LG medium to model metabolic stress conditions thought to occur in MS lesions. ${ }^{12,13}$ As shown in figure 5A, there is only a low level of cell death under $\mathrm{N} 1$ conditions at day 2 in culture. Levels modestly increase under LG conditions, as previously described. ${ }^{12,13}$ By day 6, however, there was a significant increase in cell death under LG conditions. The percent of O4 cells showing nuclear depletion of TDP-43 was significantly increased in the LG-treated cultures compared with the $\mathrm{N} 1$ counterparts (mean $46 \%$ for LG vs $17 \%$ for N1; $p=$ $0.032, n=4$, figure 5B and illustrated in figure 5C). Nuclear depletion was observed in virtually all $\mathrm{PI}^{+}$cells, as shown 
Mixed active/inactive and demyelinating lesion (MS\#10)

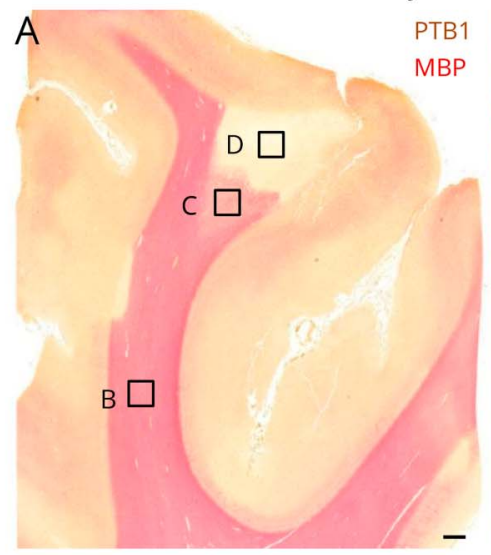

PTB1/CNPase
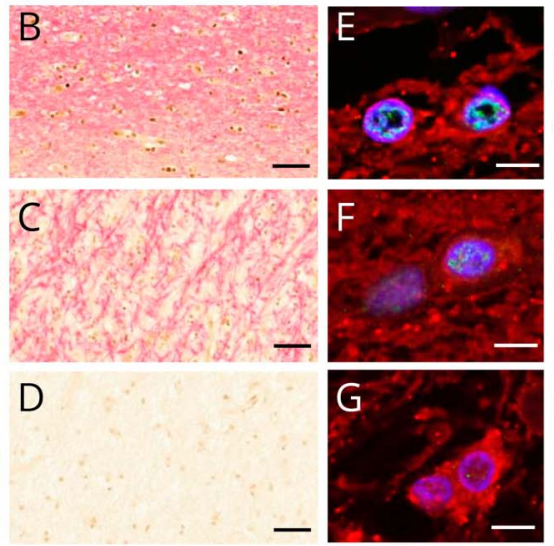

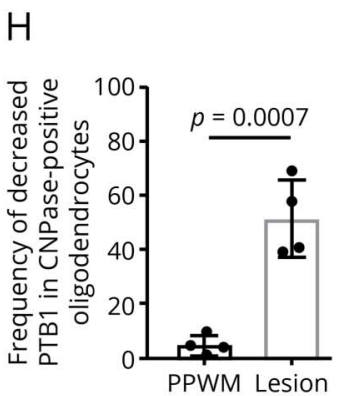

PPWM Lesion

Mixed active/inactive and demyelinating lesion (MS\#6)
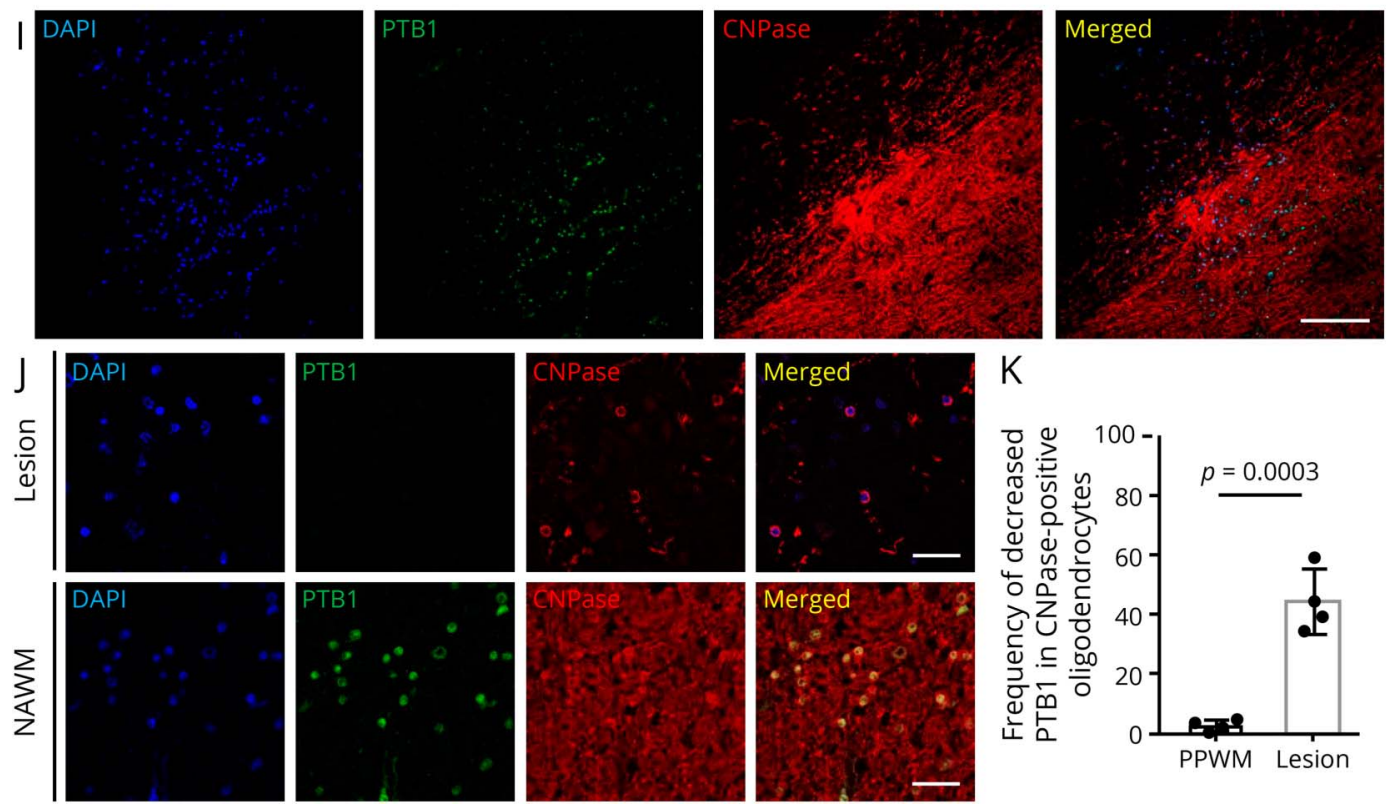

(A-H) Mixed active/inactive and demyelinating subcortical white matter lesion from MS\#10. (A-D) Double immunostaining for PTB1 (brown) and MBP (pink). (A) Macroscopic view of demyelinating subcortical lesion. Immunoreactivity for MBP is sharply demarcated in a subcortical area that has no detectable PTB1. (B) Immunoreactivity for PTB1 is present in the nucleus of glial cells, including oligodendrocytes, in NAWM. (C) Nuclear expression of PTB1 is diminished in an incompletely remyelinated area. (D) Expression of PTB1 is markedly decreased in glial cell nuclei in the demyelinated lesion. (E-G) Double immunofluorescence for PTB1 and CNPase. Although immunoreactivity for PTB1 is preserved in the nuclei of CNPase-positive oligodendrocytes in NAWM (E), nuclear PTB1 is decreased in the remyelinated area (F) and markedly depleted in oligodendrocytes in the lesion center (G). (H) Frequency of decreased PTB1 expression in CNPase-positive oligodendrocytes. Decreased PTB1 in oligodendrocytes is significantly more frequent in demyelinating lesions than PPWM. (I-K) Mixed active/inactive and demyelinating white matter lesion from MS\#6. (I) Double immunofluorescence shows that nuclear expression of PTB1 is markedly diminished in the demyelinating lesion. (J) Higher magnification of PTB1 expression in the demyelinating lesion and NAWM. Although PTB1 is localized in nuclei of CNPase-positive oligodendrocytes of NAWM, PTB1 is decreased in CNPase-positive oligodendrocytes of the demyelinating lesion. (K) Decreased PTB1 expression in oligodendrocytes in active-inactive demyelinating lesions is significantly more frequent than in PPWM. Scale bars: $1 \mathrm{~mm}(\mathrm{~A}), 100 \mu \mathrm{m}(\mathrm{I}), 50 \mu \mathrm{m}(\mathrm{B}-\mathrm{D}), 20 \mu \mathrm{m}(\mathrm{J}), \mathrm{and} 10 \mu \mathrm{m}(\mathrm{E}-\mathrm{G})$. NAWM = normal-appearing white matter; $\mathrm{DAPI}=$ 4',6-diamidino-2-phenylindole; MBP = myelin basic protein; PPWM = periplaque white matter; PTB = polypyrimidine tract-binding protein.

with the $\mathrm{PI}^{+}$cells in figure 5C. Of note, the percent of $\mathrm{PI}^{-}$ cells with nuclear depletion was greater in LG cultures vs N1 cultures (mean $44 \%$ for LG vs $14 \%$ for $\mathrm{N} 1 ; p=0.014, \mathrm{n}=3$, data not shown).

\section{Discussion}

Abnormalities of expression and localization of RBPs have been described in a number of diseases, including ALS, Huntington disease, and viral infections. ${ }^{1}$ In the present study, we focused on TDP-43, FUS, and PTB because these RBPs have an important impact on RNA biology and also because their mislocalization is thought to influence the pathogenesis of ALS and TMEV infections.

TDP-43 is a ubiquitously expressed RBP that predominantly resides in the nucleus, but shuttles across the nuclear membrane in association with messenger RNAs (mRNAs). ${ }^{15} \mathrm{~A}$ hallmark of almost all cases of ALS is disruption of nucleocytoplasmic trafficking with resultant nuclear depletion, 
Mixed active/inactive and demyelinating lesion (MS\#2)
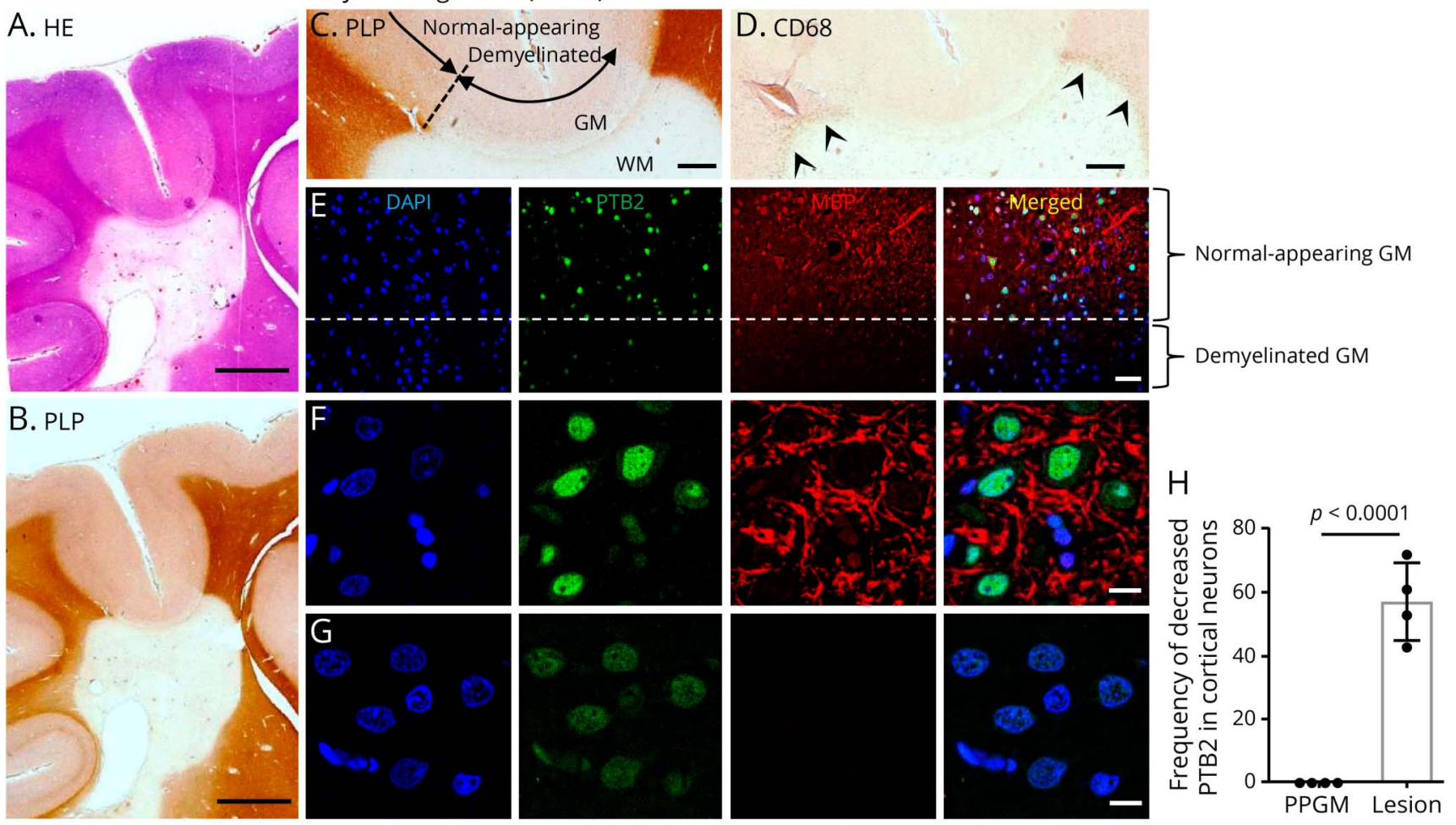

Mixed active/inactive and demyelinating lesion (MS\#10)
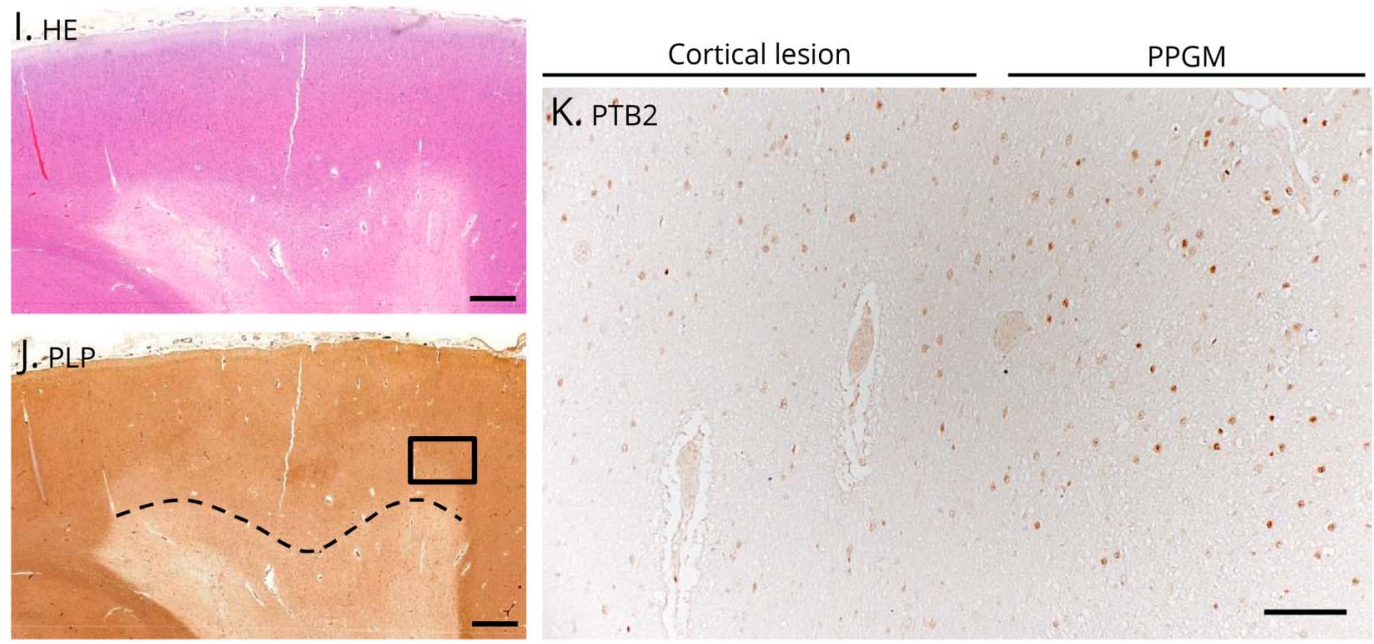

Cortical lesion

PPGM
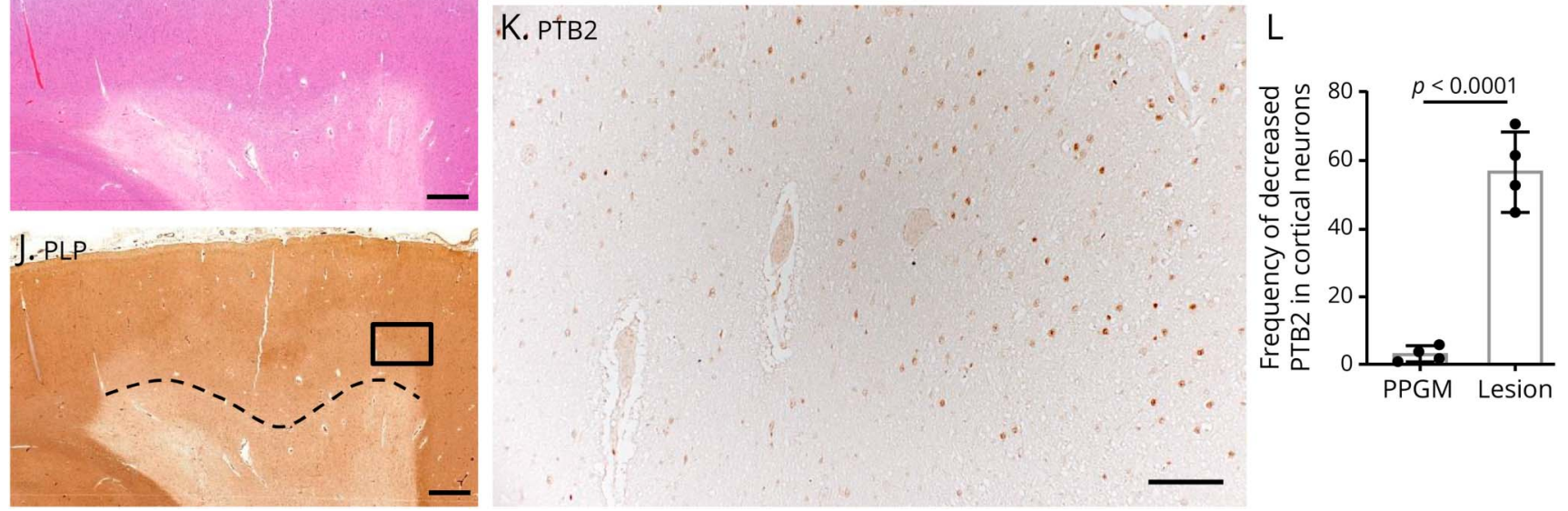

(A and B) Serial sections of a mixed active/inactive demyelinating lesion. (A) Hematoxylin and eosin stain shows hypocellularity, and (B) immunostaining for proteolipid protein shows sharply demarcated periventricular demyelination. (C) High magnification view of gray/white matter (GM/WM) interface shown in panel B. Cortical demyelination is seen in the GM. The dashed line shows the approximate boundary between normal-appearing GM and demyelinated GM. (D) CD68-positive macrophages are restricted to the periphery of the lesion (arrowheads). (E) High magnification with immunofluorescent staining of the region of the dashed line (at edge of cortical demyelination) shown in panel C. Above the dashed line in the normalappearing GM, PTB2 has a normal nuclear expression in neurons. In contrast, the expression of PTB2 is markedly decreased in neurons in the demyelinated GM below the dashed line. ( $F$ and G) Higher-magnification view of the region shown in panel $E$. ( $F$ ) Normal-appearing (myelinated) GM, which is above the dashed line, shows normal expression of PTB2 in the nuclei of neurons. In contrast, $(\mathrm{G})$, which is the demyelinated GM below the dashed line, shows decreased PTB2 expression in nuclei of neurons. (H) Frequency of decreased PTB2 expression in cortical neurons. Decreased PTB2 in cortical neurons is significantly more frequent in cortical demyelinating lesions than the PPGM. (I-L) Leukocortical mixed active/inactive demyelinating lesion MS\#10. (I) Hematoxylin and eosin stain shows subcortical WM lesion. (J) A region of the cortex above the dashed line and within the lesion is demyelinated. (K) A higher magnification of the region within the rectangle in panel I includes the boundary of cortical demyelination. PTB2 expression is diminished in the demyelinated region of the cortex, whereas PTB2 is preserved in the cortical neurons in the same layer of the PPGM. (L) Frequency of decreased PTB2 expression in cortical neurons. Decreased PTB2 in cortical neurons is significantly more frequent in cortical demyelinating lesions than the PPGM. Scale bars: $5 \mathrm{~mm}$ (A and B), $1 \mathrm{~mm}(\mathrm{C}, \mathrm{D}, \mathrm{l}$, and J), $100 \mu \mathrm{m}(\mathrm{K}), 50 \mu \mathrm{m}$ (E), and $10 \mu \mathrm{m}$ (F and G). DAPI = 4',6-diamidino-2phenylindole; GM = gray matter; $\mathrm{PLP}=$ proteolipid protein; $\mathrm{PPGM}=$ periplaque gray matter; $\mathrm{PTB}=$ polypyrimidine tract-binding protein; WM = white matter. 
A

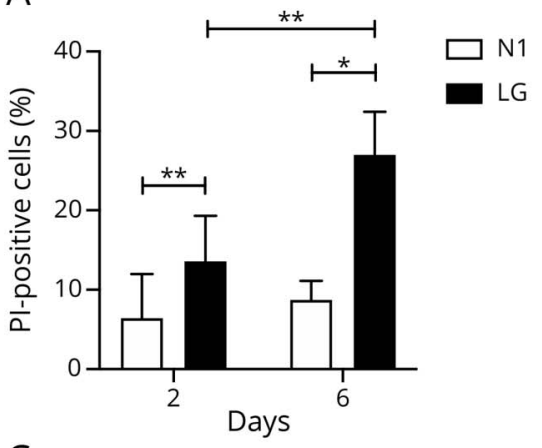

C

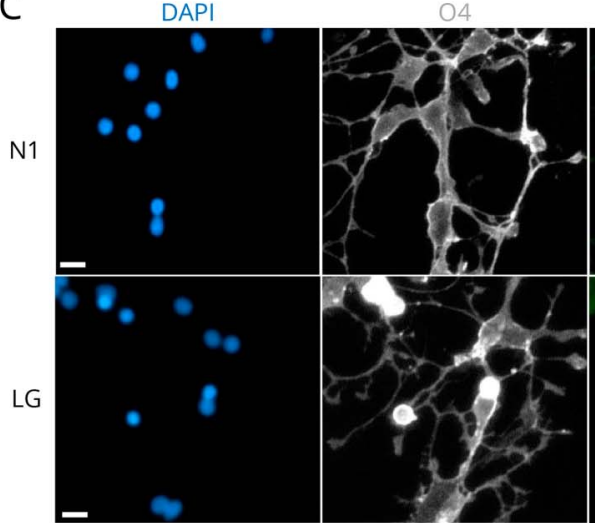

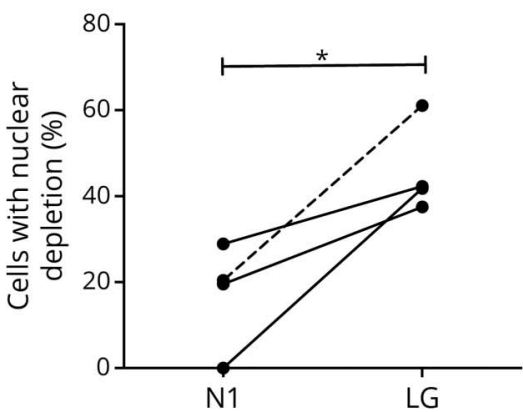

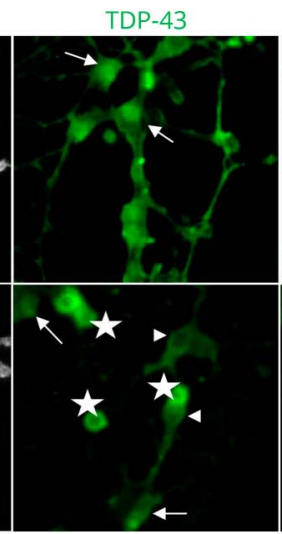

TDP-43/PI

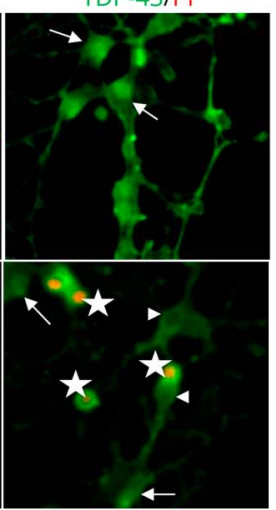

Data were derived from 3 adult cases and 1 pediatric case with no history of MS. (A) Cell death of human oligodendrocytes was assessed using $P$ staining at 2 and 6 days under optimal (N1) and metabolic stress (LG) culture conditions. (B) Depletion of nuclear expression of TDP-43 in cultures of oligodendrocytes after 2 days of treatment with LG compared with N1 condition. Solid lines (adult cases) and dashed line (pediatric case) connect cultures of oligodendrocytes obtained from the same biopsy tissue. (C) Representative images showing immunostained oligodendrocytes 2 days under N1 and LG conditions. From left side: DAPI (blue), O4 (gray), TDP-43 (green), and TDP-43 merged with PI (green and red, respectively). Arrows show cells with nuclear expression of TDP-43; arrowheads show TDP-43 nuclear-depleted $\mathrm{PI}^{-}$cells; stars show TDP-43 nuclear-depleted $\mathrm{PI}^{+}$cells. Scale bar $=10 \mu \mathrm{m} .{ }^{*} p<0.05, * \star p<0.01$. DAPI $=4{ }^{\prime}, 6$ diamidino-2-phenylindole; $\mathrm{LG}=$ low glucose; $\mathrm{PI}=$ propidium iodide; TDP-43 = transactivation response DNA-binding protein of $43 \mathrm{kDa}$. cytoplasmic mislocalization, aggregation, cleavage, and phosphorylation of TDP-43 in neural cells. ${ }^{16-18}$ The decreased expression and mislocalization or TDP-43 are thought to cause abnormalities of splicing and RNA metabolism and add to nucleocytoplasmic transport disruption, thereby contributing to ALS pathogenesis. ${ }^{19-22}$ It is likely that cytoplasmic mislocalization of other RBPs in addition to TDP-43 adds to the cellular dysfunction in ALS. ${ }^{23}$

In the present study, we demonstrate a number of abnormalities in expression and localization of RBPs in MS lesions and in in vitro cultured oligodendrocytes. We found that TDP-43 was mislocalized in oligodendrocytes in demyelinated lesions in MS, as was the case in TMEV infections. Of note, TDP-43 is known to bind to 100 s of mRNAs, including mRNAs encoding proteolipid protein, myelin basic protein, myelin oligodendrocyte glycoprotein, and myelin-associated glycoprotein, and to play a key role in RNA metabolism and splicing. ${ }^{21}$ Importantly and relevant to our findings is a recent report that an experimental decrease in expression of TDP-43 in mature oligodendrocytes in mice leads to demyelination and RIPK1mediated necroptosis of oligodendrocytes ${ }^{5}$; of note, necroptosis has been reported to occur in MS and experimental models of MS. ${ }^{24}$ In the case of ALS, TDP-43 nuclear depletion and mislocalization are associated with posttranslational modifications of this protein and rarely are a result of mutation of this gene; however, the study of Wang et al. ${ }^{5}$ indicates that TDP-43 knockdown alone can lead to a reduction in myelin gene expression and is indispensable for oligodendrocyte survival and myelination. These findings of Wang et al. ${ }^{5}$ suggest that nuclear depletion and mislocalization of TDP-43 in MS lesions would similarly lead or contribute to demyelination and, in some cases, death of oligodendrocytes.

We found a decrease in PTB1 in oligodendrocytes in mixed active/inactive demyelinating lesions and a decrease in PTB2 in neurons in cortical plaques. PTB1 and PTB2 are paralogous RBPs that are encoded by related genes. ${ }^{6}$ PTB 1 is not expressed in mature neurons and muscle, whereas PTB2 is expressed in these cells and others. These RBPs function in regulating alternative splicing and also play a role in translation, mRNA stability, and polyadenylation. The control of splicing is especially important in the CNS because of the myriad of mRNA isoforms that have key roles in development and function. Splicing in oligodendrocytes and neurons in MS demyelinated regions is likely affected by the nuclear depletion and cytoplasmic mislocalization of PTB. Importantly, PTB is involved in the differentiation of neural precursor cells. ${ }^{6,7}$ In this way, PTB2 nuclear depletion and cytoplasmic mislocalization in neurons of cortical plaques may contribute to neurodegeneration and the cognitive decline associated with MS.

In summary, we found that there is disruption of TDP-43 and PTB expression and localization that varies in different neural cell types in MS plaques. It is not unlikely that other RBPs are depleted in the nucleus and mislocalized to the cytoplasm in 
MS; however, the important known activities of TDP-43 and PTB suggest that the abnormalities we identified in these 2 RBPs will have significant effects. This variation may have resulted from differences in the protein composition of the nuclear pore complex in different cell types. ${ }^{25}$ Furthermore, different subtypes of MS lesions may manifest continuing changes of RBP abnormalities over time because of the dynamic nature of demyelinating lesions and the varying inflammatory milieu. It may be that this changeable and very dynamic nature of MS lesions may have been the reason that active plaques from MS\#14 had a normal localization of TDP-43. Also of importance is the fact that MS is a heterogeneous disease-and therefore, it is not surprising that forms of MS that are different from classical and typical cases may not share the same RBP abnormalities seen in more prototypic cases of MS. Perhaps this was the reason that an active plaque from a biopsy from a tumefactive lesion of MS\#4 (in a patient who had only 1 additional clinical problem over decades of observation) had a normal localization of TDP-43 (table e-1, links.lww.com/ NXI/A220).

The nucleocytoplasmic transport abnormalities in MS that we identified may have resulted from a number of possible causes. Probably most relevant are reports that inflammation can lead to mislocalization of proteins in neural cells. Correia et al. ${ }^{26}$ found that mislocalization of TDP-43 occurred in: cultured microglia and astrocytes following exposure to lipopolysaccharide (LPS), motor neuron-like NSC-34 cells after treatment with tumor necrosis factor alpha ( $\mathrm{TNFa}$ ), and motor neurons of mutant TDP-43 transgenic mice following LPS intraperitoneal injections. Kim et al. ${ }^{27}$ reported that treating neuronal cultures with glutamate and TNFa led to mislocalization of HDAC1 with resultant axonal damage. The latter investigators also detected abnormal cytoplasmic localization of HDAC1 in damaged axons in patients with MS and in mice with cuprizone-induced demyelination. Salapa et al. $^{28}$ found that interferon- $\gamma$ led to cytoplasmic mislocalization of heterogeneous nuclear ribonucleoprotein (hnRNP) Al, an RBP. These investigators also reported that neurons in a region of an MS brain (in which no pathology was described) had nuclear depletion and cytoplasmic mislocalization of hnRNP Al, which was aggregated in stress granules. A more recent publication by Salapa et al. ${ }^{29}$ found mislocalization of hnRNP A1 and TDP-43 in spinal cord neurons in experimental allergic encephalomyelitis; the hnRNP A1 mislocalization correlated with the clinical score and presence of infiltrates of $\mathrm{CD}^{+}$cells secreting interferon- $\gamma$.

Our in vitro culture conditions were selected to model metabolic stress conditions that are thought to occur in MS lesions. ${ }^{12,13}$ Cui et al. previously showed that these conditions were associated with an initial withdrawal of cell processes, modeling the dying-back of oligodendrocyte processes observed in MS lesions (and cuprizone-induced demyelination) ${ }^{30}$ and TMEV-induced demyelination. ${ }^{31}$ These changes were reversible if culture conditions were restored within a subsequent 48 hours. If continued past this time, however, significant cell death occurs by 6 days, as shown in figure 5A, with activation of an autophagy response. In the current study, we found TDP-43 nuclear depletion was increased under LG conditions after 2 days in culture, a time when cell death levels as detected by PI staining were low. Importantly, we specifically observed nuclear depletion in cells that were still PI negative, in addition to $\mathrm{PI}^{+}$cells that also showed nuclear depletion of TDP-43. One of the oligodendrocyte cultures was obtained from a child. Although oligodendrocyte metabolism varies depending on the age of the individual, the results from the pediatric case importantly parallel those of the 3 adults.

The in vitro oligodendrocyte results are consistent with in situ data showing nuclear depletion of TDP-43 in oligodendrocytes with intact oligodendrocyte cell bodies. Furthermore, TNFa has been found to lead to dying-back of cultured oligodendrocytes, although in this case, it was observed in newborn rat-derived oligodendrocytes. ${ }^{12}$ The combined in vitro and in situ results suggest that the TDP-43 nuclear depletion reflects a cellular stress response that could be mediated both by metabolic conditions and inflammatory mediators of MS lesions. Of note, no difference in TDP-43 transcripts was found in a microarray data set derived from oligodendrocytes under N1 vs LG conditions for 2 days, ${ }^{12}$ suggesting that any change in TDP-43 protein levels is a result of translational regulation, perhaps from stress, such as from $\mathrm{LG}^{32}$ or inflammatory factors, triggering the integrated stress response. Activation of the integrated stress response has been previously implicated in the pathogenesis of MS. ${ }^{33}$

Our results suggest that correcting the expression and localization of RBPs in MS may ameliorate disease. In addition, this direction may lead to normal localization of key transcription factors and proteins that are required for efficient myelination and remyelination in oligodendrocytes and oligodendrocyte precursor cells. ${ }^{34-37}$ Importantly, nuclear export inhibitors have been found to attenuate myelin oligodendrocyte glycoprotein-induced experimental autoimmune encephalomyelitis (and kainic acid-induced axonal damage) by limiting areas of myelin damage, preserving myelinated and unmyelinated axon integrity, and decreasing inflammation. ${ }^{38}$ Nuclear export inhibitors have also been found to attenuate disease and to be neuroprotective in experimental models of ALS, ${ }^{39}$ including a mutant TDP-43 mouse model, ${ }^{19}$ and Huntington disease ${ }^{40}$ (which, like ALS, has abnormalities of nucleocytoplasmic transport). Furthermore, nucleocytoplasmic transport is being targeted in patients with cancer in addition to neurologic diseases-and a clinical trial with a nuclear export inhibitor is in progress in ALS.

Altered nucleocytoplasmic transport leading to abnormal expression and mislocalization of RBPs and other macromolecules may not only contribute to the demyelination and neurodegeneration in MS, but also underlie a number of other disease states, both infectious and noninfectious. The availability of drugs that target nucleocytoplasmic transport may 
provide new and novel treatment possibilities for these disorders.

\section{Acknowledgment}

The authors thank the UCLA Human Brain and Spinal Fluid Resource Center and the Rocky Mountain MS Center Tissue Bank (supported in part by a grant from the National Multiple Sclerosis Society) for specimens from autopsied MS cases.

\section{Study funding}

NIH National Institute of NINDS (R21NS096569) (RPR), Amyotrophic Lateral Sclerosis Association (RPR), Progressive MS Alliance (BRAVEin MS) (J.P.A.), Lohengrin Foundation, Steps4 Doug, John and Patricia McDonald, and Barbara and Marc Posner.

\section{Disclosure}

K. Masaki, Y. Sonobe, G. Ghadge, P. Pytel, P. Lépine, F. Pernin, Q.-L. Cui, J.P. Antel, S. Zandee, A. Prat, and R.P. Roos report no disclosures. Go to Neurology.org/NN for full disclosures.

\section{Publication history}

This manuscript was previously posted on bioRxiv: doi: 10.1101/829457. Received October 28, 2019. Accepted in final form February 7, 2020.

Appendix Authors

\begin{tabular}{|c|c|c|}
\hline Name & Location & Contribution \\
\hline $\begin{array}{l}\text { Katsuhisa } \\
\text { Masaki, MD, } \\
\text { PhD }\end{array}$ & $\begin{array}{l}\text { University of Chicago } \\
\text { Medical Center }\end{array}$ & $\begin{array}{l}\text { Conception and design of } \\
\text { the study and drafting of } \\
\text { the manuscript }\end{array}$ \\
\hline $\begin{array}{l}\text { Yoshifumi } \\
\text { Sonobe, PhD }\end{array}$ & $\begin{array}{l}\text { University of Chicago } \\
\text { Medical Center }\end{array}$ & $\begin{array}{l}\text { Conception and design of } \\
\text { the study }\end{array}$ \\
\hline $\begin{array}{l}\text { Ghanashyam } \\
\text { Ghadge, PhD }\end{array}$ & $\begin{array}{l}\text { University of Chicago } \\
\text { Medical Center }\end{array}$ & $\begin{array}{l}\text { Conception and design of } \\
\text { the study }\end{array}$ \\
\hline $\begin{array}{l}\text { Peter Pytel, } \\
\text { MD }\end{array}$ & $\begin{array}{l}\text { University of Chicago } \\
\text { Medical Center }\end{array}$ & $\begin{array}{l}\text { Acquisition of samples } \\
\text { and analysis of the data }\end{array}$ \\
\hline $\begin{array}{l}\text { Paula Lépine, } \\
\text { MSc }\end{array}$ & $\begin{array}{l}\text { Centre du Recherche du } \\
\text { Centre Hospitalier de } \\
\text { l'Université de Montréal }\end{array}$ & $\begin{array}{l}\text { Acquisition of samples } \\
\text { and analysis of the data }\end{array}$ \\
\hline $\begin{array}{l}\text { Florian } \\
\text { Pernin, MSc }\end{array}$ & McGill University & $\begin{array}{l}\text { Acquisition of samples } \\
\text { and analysis of the data } \\
\text { and drafting of the } \\
\text { manuscript }\end{array}$ \\
\hline $\begin{array}{l}\text { Qiao-Ling Cui, } \\
\text { MD, PhD }\end{array}$ & McGill University & $\begin{array}{l}\text { Acquisition of samples } \\
\text { and analysis of the data }\end{array}$ \\
\hline $\begin{array}{l}\text { Jack P. Antel, } \\
\text { MD }\end{array}$ & McGill University & $\begin{array}{l}\text { Acquisition of samples } \\
\text { and analysis of the data }\end{array}$ \\
\hline $\begin{array}{l}\text { Stephanie } \\
\text { Zandee, PhD }\end{array}$ & $\begin{array}{l}\text { Centre du Recherche du } \\
\text { Centre Hospitalier de } \\
\text { I'Université de Montréal }\end{array}$ & $\begin{array}{l}\text { Acquisition of samples } \\
\text { and analysis of the data }\end{array}$ \\
\hline $\begin{array}{l}\text { Alexandre } \\
\text { Prat, MD, PhD }\end{array}$ & $\begin{array}{l}\text { Centre du Recherche du } \\
\text { Centre Hospitalier de } \\
\text { I'Université de Montréal }\end{array}$ & $\begin{array}{l}\text { Acquisition of samples } \\
\text { and analysis of the data }\end{array}$ \\
\hline $\begin{array}{l}\text { Raymond P. } \\
\text { Roos, MD }\end{array}$ & $\begin{array}{l}\text { University of Chicago } \\
\text { Medical Center }\end{array}$ & $\begin{array}{l}\text { Conception and design of } \\
\text { the study and drafting the } \\
\text { manuscript }\end{array}$ \\
\hline
\end{tabular}

\section{References}

1. Nussbacher JK, Batra R, Lagier-Tourenne C, Yeo GW. RNA-binding proteins in neurodegeneration: seq and you shall receive. Trends Neurosci 2015;38:226-236. doi: $210.1016 /$ j.tins.2015.1002.1003.

2. Michiels T, Roos RP. Theiler's virus central nervous system infection. In: Ehrenfeld E, Domingo E, Roos RP, editors. The Picornaviruses. Washington, DC: ASM Press; 2010:411-430.

3. Pilipenko EV, Viktorova EG, Guest ST, et al. Cell-specific proteins regulate viral RNA translation and virus-induced disease. EMBO J 2001;20:6899-6908. doi: 6810.1093/ emboj/6820.6823.6899.

4. Masaki K, Sonobe Y, Ghadge G, et al. TDP-43 proteinopathy in Theiler's murine encephalomyelitis virus infection. PLoS Pathog 2019;15:e1007574.

5. Wang J, Ho WY, Lim K, et al. Cell-autonomous requirement of TDP-43, an ALS/ FTD signature protein, for oligodendrocyte survival and myelination. Proc Natl Acad Sci USA 2018;115:E10941-E10950. doi: 10910.11073/pnas.1809821115.

6. $\mathrm{Hu}$ J, Qian $\mathrm{H}, \mathrm{Xue} \mathrm{Y}, \mathrm{Fu} \mathrm{XD}$. PTB/nPTB: master regulators of neuronal fate in mammals. Biophys Rep 2018;4:204-214.

7. Linares AJ, Lin $\mathrm{CH}, \mathrm{Damianov} \mathrm{A}$, et al. The splicing regulator PTBP1 controls the activity of the transcription factor $\mathrm{Pbx1}$ during neuronal differentiation. Elife 2015;4: e09268.

8. Polman CH, Reingold SC, Banwell B, et al. Diagnostic criteria for multiple sclerosis: 2010 revisions to the McDonald criteria. Ann Neurol 2011;69:292-302.

9. Dhaeze $\mathrm{T}$, Tremblay L, Lachance $\mathrm{C}$, et al. CD70 defines a subset of proinflammatory and CNS-pathogenic TH1/TH17 lymphocytes and is overexpressed in multiple sclerosis. Cell Mol Immunol 2019;16:652-665.

10. Kuhlmann T, Ludwin S, Prat A, Antel J, Brück W, Lassmann H. An updated histological classification system for multiple sclerosis lesions. Acta Neuropathol 2017;133:13-24.

11. Garcia-Cabezas MA, John YJ, Barbas H, Zikopoulos B. Distinction of neurons, glia and endothelial cells in the cerebral cortex: an algorithm based on cytological features. Front Neuroanat 2016;10:107

12. Cui QL, Khan D, Rone M, et al. Sublethal oligodendrocyte injury: a reversible condition in multiple sclerosis? Ann Neurol 2017;81:811-824.

13. Rone MB, Cui QL, Fang J, et al. Oligodendrogliopathy in multiple sclerosis: low glycolytic metabolic rate promotes oligodendrocyte survival. J Neurosci 2016;36: 4698-4707.

14. Boutz PL, Stoilov $\mathrm{P}, \mathrm{Li} \mathrm{Q}$ et al. A post-transcriptional regulatory switch in polypyrimidine tract-binding proteins reprograms alternative splicing in developing neurons. Genes Dev 2007;21:1636-1652. doi: 1610.1101/gad.1558107.

15. Buratti E, Brindisi A, Giombi M, et al. TDP-43 binds heterogeneous nuclear ribonucleoprotein $\mathrm{A} / \mathrm{B}$ through its $\mathrm{C}$-terminal tail: an important region for the inhibition of cystic fibrosis transmembrane conductance regulator exon 9 splicing. J Biol Chem 2005;280:37572-37584.

16. Neumann M, Sampathu DM, Kwong LK, et al. Ubiquitinated TDP-43 in frontotemporal lobar degeneration and amyotrophic lateral sclerosis. Science 2006;314:130-133.

17. Arai T, Hasegawa M, Akiyama H, et al. TDP-43 is a component of ubiquitin-positive tau-negative inclusions in frontotemporal lobar degeneration and amyotrophic latera sclerosis. Biochem Biophys Res Commun 2006;351:602-611.

18. Igaz LM, Kwong LK, Xu Y, et al. Enrichment of C-terminal fragments in TAR DNA binding protein- 43 cytoplasmic inclusions in brain but not in spinal cord of frontotemporal lobar degeneration and amyotrophic lateral sclerosis. Am J Pathol 2008;173: 182-194.

19. Chou CC, Zhang Y, Umoh ME, et al. TDP-43 pathology disrupts nuclear pore complexes and nucleocytoplasmic transport in ALS/FTD. Nat Neurosci 2018;21: 228-239.

20. Lagier-Tourenne C, Polymenidou M, Cleveland DW. TDP-43 and FUS/TLS: emerging roles in RNA processing and neurodegeneration. Hum Mol Genet 2010;19: R46-R64.

21. Polymenidou M, Lagier-Tourenne C, Hutt KR, et al. Long pre-mRNA depletion and RNA missplicing contribute to neuronal vulnerability from loss of TDP-43. Nat Neurosci 2011;14:459-468.

22. Purice MD, Taylor JP. Linking hnRNP function to ALS and FTD pathology. Front Neurosci 2018;12:326.

23. Conlon EG, Fagegaltier D, Agius P, et al. Unexpected similarities between C9ORF72 and sporadic forms of ALS/FTD suggest a common disease mechanism. Elife 2018; 37754. doi: 37710.37554/eLife.37754.

24. Ofengeim D, Ito Y, Najafov A, et al. Activation of necroptosis in multiple sclerosis. Cell Rep 2015;10:1836-1849. doi: 1810.1016/j.celrep.2015.1802.1051.

25. Raices M, D'Angelo MA. Nuclear pore complex composition: a new regulator of tissue-specific and developmental functions. Nat Rev Mol Cell Biol 2012;13:687-699. doi: $610.1038 / \mathrm{nrm} 3461$.

26. Correia AS, Patel P, Dutta K, Julien JP. Inflammation induces TDP-43 mislocalization and aggregation. PLoS One 2015;10:e0140248. doi: 0140210.0141371/journal.pone. 0140248.

27. Kim JY, Shen S, Dietz K, et al. HDAC1 nuclear export induced by pathological conditions is essential for the onset of axonal damage. Nat Neurosci 2010;13: 180-189.

28. Salapa HE, Johnson C, Hutchinson C, et al. Dysfunctional RNA binding proteins and stress granules in multiple sclerosis. J Neuroimmunol 2018;324:149-156. doi: 10. 1016/j.jneuroim.2018.1008.1015.

29. Salapa HE, Libner CD, Levin MC. Dysfunctional RNA-binding protein biology and neurodegeneration in experimental allergic encephalomyelitis. J Neurosci Res 2019; 98:704-717. doi: 10.1002/jnr.24554. 
30. Ludwin SK, Johnson ES. Evidence for a "dying-back" gliopathy in demyelinating disease. Ann Neurol 1981;9:301-305.

31. Rodriguez M. Virus-induced demyelination in mice: "dying back" of oligodendrocytes. Mayo Clin Proc 1985;60:433-438.

32. Yang R, Wek SA, Wek RC. Glucose limitation induces GCN4 translation by activation of Gcn2 protein kinase. Mol Cell Biol 2000;20:2706-2717.

33. Way SW, Popko B. Harnessing the integrated stress response for the treatment of multiple sclerosis. Lancet Neurol 2016;15:434-443.

34. Dai J, Bercury KK, Jin W, Macklin WB. Olig1 acetylation and nuclear export mediate oligodendrocyte development. J Neurosci 2015;35:15875-15893.

35. Gottle P, Kury P. Intracellular protein shuttling: a mechanism relevant for myelin repair in multiple sclerosis? Int J Mol Sci 2015;16:15057-15085.
36. Gottle P, Sabo JK, Heinen A, et al. Oligodendroglial maturation is dependent on intracellular protein shuttling. J Neurosci 2015;35:906-919.

37. Nakahara J, Kanekura K, Nawa M, et al. Abnormal expression of TIP30 and arrested nucleocytoplasmic transport within oligodendrocyte precursor cells in multiple sclerosis. J Clin Invest 2009;119:169-181.

38. Haines JD, Herbin $\mathrm{O}$, de la Hera B, et al. Nuclear export inhibitors avert progression in preclinical models of inflammatory demyelination. Nat Neurosci 2015; 18:511-520.

39. Zhang K, Donnelly CJ, Haeusler AR, et al. The C9orf72 repeat expansion disrupts nucleocytoplasmic transport. Nature 2015;525:56-61.

40. Grima JC, Daigle JG, Arbez N, et al. Mutant huntingtin disrupts the nuclear pore complex. Neuron 2017;94:93-107.e6. 


\section{Neurology \\ Neuroimmunology \& Neuroinflammation}

RNA-binding protein altered expression and mislocalization in MS

Katsuhisa Masaki, Yoshifumi Sonobe, Ghanashyam Ghadge, et al.

Neurol Neuroimmunol Neuroinflamm 2020;7;

DOI 10.1212/NXI.0000000000000704

This information is current as of March 26, 2020

\section{Updated Information \& Services}

References

Subspecialty Collections

Permissions \& Licensing

Reprints including high resolution figures, can be found at:

http://nn.neurology.org/content/7/3/e704.full.html

This article cites 39 articles, 9 of which you can access for free at: http://nn.neurology.org/content/7/3/e704.full.html\#\#ref-list-1

This article, along with others on similar topics, appears in the following collection(s):

All Demyelinating disease (CNS)

http://nn.neurology.org//cgi/collection/all_demyelinating_disease_cns

Autoimmune diseases

http://nn.neurology.org//cgi/collection/autoimmune_diseases

Multiple sclerosis

http://nn.neurology.org//cgi/collection/multiple_sclerosis

Information about reproducing this article in parts (figures,tables) or in its entirety can be found online at:

http://nn.neurology.org/misc/about.xhtml\#permissions

Information about ordering reprints can be found online:

http://nn.neurology.org/misc/addir.xhtml\#reprintsus

Neurol Neuroimmunol Neuroinflamm is an official journal of the American Academy of Neurology.

Published since April 2014, it is an open-access, online-only, continuous publication journal. Copyright

Copyright $\odot 2020$ The Author(s). Published by Wolters Kluwer Health, Inc. on behalf of the American

Academy of Neurology.. All rights reserved. Online ISSN: 2332-7812.

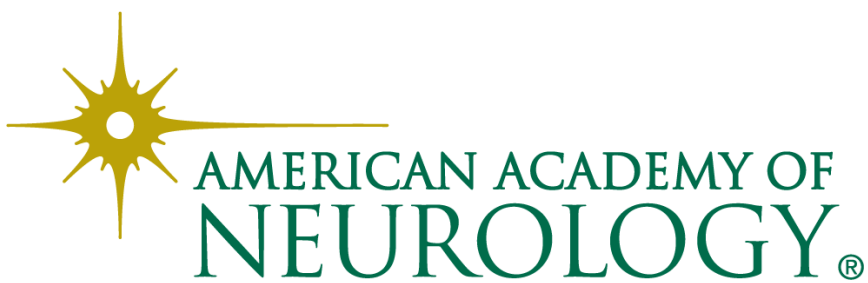

